\title{
Defining Stupidity
}

\author{
James F. Welles, Ph,D.
}

*Corresponding Author : James F. Welles, P O Box 17, East Marion, NY 11939. Mobile: 954-531-5382. Email: jwelles103@aol.com.

\section{Received date: : February 27,2018; Accepted date : March 12,2018; Published date: March 20, 2018.}

\author{
Citations : James F. Welles, Cognitive Dissonance Revisited, Journal of Psychology and Mental Health Care.2(1). DOI: 10.31579/2637-8892/024 \\ Copyright : @ 2018 James F. Welles. This is an open-access article distributed under the terms of the Creative Commons Attribution License, which \\ permits unrestricted use, distribution, and reproduction in any medium, provided the original author and source are credited.
}

We are naturally stupid. That is, we can be stupid just by being ourselves. In fact, this article is based on two fundamental contentions: we cannot really understand ourselves without understanding stupidity, and if we understand stupidity, we will understand our-selves. Although the focus of this work is on stupidity, it is really a study of how the human mind functions. Sometimes it is "Intelligent"; more often it is "Stupid", but most of the time, it, like daily life, just plugs along unobtrusively in a manner unnamed because it is so common as never to have been named anything at all. Regardless of the labels used, our characteristic interactions with the environment are all directed by the same basic mental process by which our linguistic schemas shape perception via the $n$-dox into posfed cognitions, beliefs and behavior.

In defining our mental life and shaping our behavior, the schema so routinely causes people to act in their own worst interests that stupidity can be considered one of the few, true cultural universals. Geniuses display it, superior people flaunt it, the mighty revel in it, and the average Jane accepts it. Nevertheless, it thrives unnoticed in humanity's closet of shame. As this is the age when gays,blacks and even women have come out of the closet-my, it must have been fun in that closet-perhaps it could also be the age when stupidity is acknowledged, confronted and perhaps even understood. Considering its impact on history, stupidity certainly deserves a hearing which is at least fair if not equal to that granted intelligence.

Traditionally, historians have pleased their readers with accounts of humanity's wondrous intellect. These generally placed humans, as Mr. Clemens' boy Sam once observed, "Somewhere between the angels and the French". Likewise, psychologists followed the path of greatest acceptance in their concentration on intelligence to the total disregard of stupidity, as a cursory look at the index of any general psychology text will reveal: intelligence is broken down into scores of subheadings; stupidity is not even listed. A Martian prepping for a visit to earth by reading a psych text would assume there is a whole lot of intelligence on the planet and not have a clue that a thing like stupidity even exists much less commonly occurs.

Considering how little intelligence and how much stupidity there is, it really is incredible that this imbalance in the scientific literature has existed for so long. Whatever the cause for this condition, it cannot be that stupidity is not a fit topic for scientific investigation because if it is not, then neither is intelligence. However, the one is totally neglected and the other virtually pounded into the ground. If we really want to have a full understanding of the human experience, we will finally have to acknowledge, examine and finally un-derstand that which is both embarrassing and shameful.
Fortunately, knowledge of stupidity is not limited to what historians and psychologists have not written about it. Herodotus noted that man was robbed of reason by "Infatuation". Of course, in ancient Greece deities were responsible for everything, and in this particular matter, it was the goddess Ate who was responsible for infatuation, mischief, delusion and folly - apparently everything contributing to maladaptation but stupidity. She rendered her victims "Incapable of rational choice" and blind to distinctions of morality and expedience. (N.b. this moral dimension of Ate's influence.)

Biblically, the 14th Psalm begins with a reference to an impious fool, and stupid men are condemned in Proverbs 7-8, although stupidity is personified as a lady (9:13). Wisdom, which starts with fear of the Lord (Psalm 111:10), and folly are compared in Ecclesi-astes 711. Wisdom and knowledge are God given (2:26), but the reader is advised not to get overwise (7:16-17). This unlikelihood is, presumably, because the fool and wise man -who will not be able to discover knowledge and find truth on his own (8:16-17) since wisdom is beyond his grasp (7:24)-end up even (i.e., dead).

In the Christian tradition generally, stupidity, blunder andfolly were diplomatically glossed over by Jesus in deference to the sensibilities of the members of his flock, who were remarkably ignorant if not foolish. Indeed, in his Sermon on the Mount, Jesus has been accused of promoting stupidity, docility and blind obedience in hisfollowers. With membership in the denomination dependent on the acceptance of a savior who was born of a virgin and rose from the dead,Christians are often regarded as fools by the wise of the world althoughspecifically advised not to engage in stupid banter nor to be fools. Among themselves, criticism of human idiocy was discouraged so they came to regard the truth about a fool as a type of indecent exposure and most definitely taboo. What other major religions of the world have to say about stupidity will not become clear until the beckoning field of comparative stupidity comes to flower, but the Christian "Don't ask; don't answer" attitude certainly contributes to the nearly empty shelves in Western libraries where the scores/hundreds of books on stupidity should be.

Literature: Those shelves are, fortunately, only "Nearly" empty, because despite the taboo, there have been a few pioneers who dared delve into the topic. First, of course, there were a couple of Germans. In 1909, Dr. Leopold Löwenfeld had Über die Dummheit published. In this work, stupidity was not defined from a medical viewpoint, but rather its broad forms were classified as multidimensional functional failings of a faulty intellect-meaning dullness, weak character, inattention, misperception, poor judgment, clumsy associations, bad memory, etc. 
As might be expected, one of the sexes and one of the races was less stupid than the others, and although the book was updated in 1921, even World War I could not shake the author's con-viction about the sexual/racial distribution of stupidity. He might well have inferred that white men were superior in stupidity, but for some reason, he not too objectively concluded instead everyone else was generally inferior in intellect.

Following Leopold's lead, Max Kemmerich had Aus der Geschichte der menschlichen Dummheit published in 1912. A Teu-tonic cure for insomnia, this work examines stupidity in a Biblical context and is essentially an attack on established religions. Max's emphasis ona belief system was well placed, but his work is intol-erantly narrow in that he recognized the Holy Bible as the only legiti-mate standard for belief and behavior.

In 1919, psychologist Charles Richet had L'homme stupide published. He dodged the issue of defining or classifying stupidity but dealt with the idiocies of drugs, wealth, feudalism, slavery, war, fashion, semantics, superstitions, etc. This is more a witty compilation of thoughts and examples than a scientific treatment of the phe- nomenon and ranged so far afield that some subjects bear only a tenuous connection with the topic.

Dr. István Ráth-Végh, a retired Hungarian judge, contributed three books to the shelves. Like most other contributions, they are neither comprehensive nor analytical but do comprise 800 pages of source material for any reader of Hungarian in need of examples of idiocy grouped under convenient headings. Published at the rate of one per year from 1938 through 1940, only the first found its way into English: From the History of Human Folly (1963).

The first book in English on the topic was A Short Introduction to the History of Human Stupidity (1932), by Walter Pitkin. Like many books, it was misnamed, being really a breezy essay on human folly, and failed, unfortunately, to generate any general interest in the topic. That year, Barbara Swain's Fools and Folly during the Middle Ages and The Renaissance also appeared, thoroughly covering the topic during the given time frame. Then in 1959 came Paul Tabori's The Natural Science of Stupidity - a superficial if entertaining collection of anecdotes culled from history - and in 1970 John Fischer's general cultural review The Stupidity Problem, and Other Harassments.

In 2002, Dr. Robert Sternberg's misnamed volume Why Smart People Can Be So Stupid appeared-being actually not about stupidity but about the related but slightly differently de-fined topic of foolishness. It suffered from the fragmentation inherent in most edited works, but it did present a lot of research data consistent with the phenomenon of stupidity as well as provide an element of wel-comed intellectual legitimacy to the topic by virtue of the title of its author.

Although the term "Stupidity" does not appear in the title, Group-think (1982), by Irving L. Janis, belongs on the shelves next to the volumes just cited. It is concerned with a specific cause of stupidity but has some general value to anyone interested in the topic and provides a number of good case studies of how leaders make bothfaulty and sound decisions.

Finally, Barbara Tuchman's book The March of Folly (1984) rates a place with the others. Although she honors the reigning taboo against use of the word "Stupidity", preferring the cumbersome "Woodenheadedness" and newspeakish "Un-wisdom", her book provides more case studies of leaders caught up in themselves. In fact, she made a summary statement of stupidity with the perceptive comment, "Woodenheadedness, the source of self-deception, is a factor that plays a remarkably large role in government.
It consists in assessing a situation in terms of preconceived fixed notions while ignoring or rejecting any contrary signs and thus acting according to wishes without allowing one's behavior to be affected by unwelcome facts."

Stupidity as normal: When considering "Stupidity" in such works, it is important to distinguish between the word and the phenomenon. The word stems from the Latin stupere, meaning dumb or astounded and is related to "Stupor". It may be used to designate a mentality which is considered to be informed, deliberate and maladaptive. However, because of the existing taboo, this is seldom done. Usually, the term is used like an extreme swear word - a put-down for those deemed intellectually inferior, although this tactic may reveal more about the attitude of the user than the cognitive abilities of the designatee(s).

On the other hand, as a disparaging term for members of an outgroup, the word "Stupidity" often indicates little more than a biased evaluation of behavior. If we do " $\mathrm{X}$ " it is smart or nec-essary; if they do "X" it is stupid. For example, when contemplating President Reagan's "Star Wars" defense system, free-spending Democrats suddenly became fiscal conservatives, so spending on that program was deemed stupid.

As the same act may be interpreted as both stupid and reasonable (or brilliant), we do indeed live in a perceptual world of " $\mathrm{A}$ " and "Not A": that is, a statement may be true and false at the same time-e.g., "History is about people" is superficially true, but it is also about geography, economics, psychology, etc. Further, changes through time may alter prejudiced evalu-ations, so the label "Stupid" may express nothing more than a temporal estimate made according to arbitrary standards sub-jectively applied to perceived conditions. Thus, stupidity was invoked as the best explanation for the deaths of thousands of young men during WWII for no good reason over "Meaningless" bridgesreferring to those at Nijmegen (the "Bridge Too Far") and Remagen. This analysis conveniently omits the fact that, at their moments in time, these bridges were potentially if not indeed tremendously meaningful.

As a phenomenon, stupidity is most often a limited and limiting experience pattern (or, conversely, one that is over-ex-panded and overextending). In either case, it is caused by a be-lief blocking the formation or function of one more relevant to given conditions. Something in the environment is not matched in the cognitive world because the existing schema is too emotionally entrenched to permit an accurate appraisal of incoming data. First and foremost, the mind is an instrument for belief - not for knowing, learning or problem solving but for believing, and it works to thwart intelligence (i.e., the abil-ity to foresee consequences of one's actions and the capacity to restructure one's schema according to experience) no matter how upsetting that experience of profitable learning may be.

There are really two dependent aspects to schematic stupidity: one is that a schema induces stupidity, and the other is that a schema is stupid. Almost every schema induces stupidity in that it is a belief system which inhibits the formation of im-proved beliefs, functional ideas and refined perceptions. Oddly enough, even a schema of "Openmindedness" can be stupid if it inhibits the development of more accurate perceptions and an appreciation of the better ideas among thoseavailable. This is the chief drawback of the liberal schema, which tends to treat all forms of behavior, cognitions, beliefs and everything else equally whether they are actually equally good or not.

As for a schema being stupid, every one of them is by one standard or another, in that each is a compromise of the beliefs upon which a society is based, the ideas it promotes and the behavior it permits. An internally consistent schema may be repressively flat to the point of boredom for those who hold it while being maniacally disruptive to those around them. If a schema cannot motivate people to do anything more than just believe and exist, it and they may lose out tomore inspiring belief systems of competing groups. 
At the other extreme, schemas which dominated and then died litter the intellectual by-ways of history. It is really this motivational dynamic of our social nature which makes our verbal schemas inherently maladaptive and us so chronically stupid.

Rationalism: In philosophical terms, stupidity may be viewed as a three way compromise among: 1.) "Pragmatic rationality"- how well individuals maximize the satisfaction of their desires, given their schemas; 2.) "Epistemic rationality"-the internal consistency of the schemas; and 3.) "Theoretical rationality- how well the sche-mas represents the external world. All this would be much easier for cognitive theorists to understand and accept were it not for the schematic legacy of the Age of Reason.

In the eighteenth century, people sought to understand their world and achieve an accurate and internally consistent picture of its com-plexities. Rationalists thought that people, like Newton, dealt with reality in an analytical, reasonable manner, with emotions under the direction of cognitive factors and, for example, on the political front in democracies, cast an in-formed vote according to their best interest after having studied the relevant issues. Although there are very few sworn ration-alists left, due to the fact that people so frequently deviate from the norms of reason (e.g., voting irrationally according to emotions or appearances), many students of human behavior are still enthralled by the assumption that people are reasonable and wise-as in Homo "sapiens", meaning wise.

Confusion as to the relationship of wisdom to knowledge has likewise impeded our understanding of ourselves for years, proving the self-confirming point that while we are a learned animal, we are appallingly slow learners. Ironically, the greatest obstacle to our learning has not been genetic or physiological but the stock of accumulated illusions (aka "Knowledge") we have created forourselves. Evasions, suppressions, and lies have created a missive store of misinformation. Put another way, Rousseau observed that "Our minds have been corrupted in proportion" to the improvement of human knowledge. That is, the better our knowledge, the more it defines/confines us.

Two hundred years ago, rationalists believed that as we learned more about our world we would become wiser. That belief is no longer tenable. Knowledge accumulates; wisdom does not. For all our vaunted skills in communication, we still learn pretty much as do rats, with little wisdom (i.e., not intellect ) passed on from one generation to the next and even less developed by public schools- which are tasked with passing on superstitions, taboos and con-doms. Worse yet, each generation finds a new way to mess itself up because we do not behave even like knowledgeable rats. As knowledge accumulates, so do misconceptions, old wives' tales and idiotic ideas and beliefs of all sorts as well. These do as much to shape our behavior as do immediate circumstances, since it is through our cognitive world that the stimuli we perceive are interpreted, evaluated and accepted as the basis for our behavior.

The rationalists could not comprehend the nature of stupidity, intelligence or humanity because they viewed the universe asa Manichaen expression of ideals in logical conflict with their opposites good vs. evil, God vs. the Devil, etc. They did not perceive healthy behavior as a balance or blending of social needs withenvironmental conditions and group goals with syntactic limits. Rationalists did posit a superegoish ideal personality which would presumably pro-vide a perfect fit for an individual into a perfectly smug society in heaven. However, they failed to appreciate how wasteful it was to divine philosophical systems which were internally consistent but functionally useless because they existed only in splendid, cerebral isolation.
In fact, it was exactly such effete thinking that characterized the unenlightened Germanic revival of the ancient Greek tra-dition of impractical philosophy in the eighteenth century. In that age, when prevailing Christian values were being challenged if not undermined, France ruled the land, England ruled the seas and Germany ruled the air. The Teutonic schemas, so beautiful in their logical consistency, did not relate to anything real, and as Kant never quite got around to pointing out, there are really only two good, valid criticisms of pure reason - one is that it is pure; the other is that it is reasonable.

A corollary of Kant's rationalism was a naive moralism smacking of Socratic idiocy. His "Categorical imperative" is really a good old Germanic Golden Rule rather than the new version-that he who has the gold rules. The assumption is puri-ty of intent with all conflicts resolvable by good-faith reasoning while bad-faith reasoners would come around under the influ-ence of patient coaxing of good natured negotiators. This atti-tude was alive if feeble in the late 1970's as evinced by President Jimmy Carter in his benign approach to militarymatters when dealing with the hard-nosed Russians.

Intelligence: Unfortunately, the scientists in their structured roles and carefully controlled labs have been unable to do any more than the rationalists to render analysis of the nebulous concepts of human nature and intelligence realistic, functionally valuable and intellectually valid. In a purely epistemological context, "Intelligence" is the ability to process information effi-ciently-meaning, in behavioral terms, data being related with-out corruption by a prevailing schema. Such information is then ideally evaluated on the basis of intrinsic merit and credi-bility to relevant, effective reaction strategies. The amount of knowledge in a system can by indicated on a scale extending from agnostic/ignorant (having no data) to gnostic (having all relevant data). Overall efficiency of the system is measured relative to the achievement of "Appropriate" goals, whether they are explicitly intended or subconsciously hidden. The functional strategies available as possible coping responses are determined by past experience and perceived circumstances, and people are labeled "Intelligent" when the strategy employed in problem solving suits their skills and proves to be functionally successful.

Thus, in a general sense, "Intelligence" indicates the characteristic ability to apply a relevant schema so as to maximize the probability of a successful solution to a given problem in a particular context. However, as psychologists have been unable to formulate an opera-tional definition of intelligence, they have had to settle for trying to solve the problem of "Problem solving". This presumably indicates intelligence and can be broken down into a number of identifiable components.

First, a situation must be perceived as a problem. The perceived facts must then be coded in a conceptual shorthand (words) which lend themselves to mental manipulations. Relevant facts may then be integrated in an assembly reflecting functional relations. The problem can then be divided into parts through dissociation. Finally, a solution can be found through imaginative integration of verbal symbols into a new synthesis leading to an improved relationship with the functional environment.

This concise summary of the problem solving process contrasts sharply with a comparable consideration of the many faces of stupid-ity. At the grandest level of generalization, behavior may be guided by an inappropriate schema because the problem is not properly per-ceived. For example, for the audience watching a magic show, the problem for the magician is to pull a rabbit out of a hat. However, forthe magician, the problem is getting the rabbit into the hat. We will ignore the problems for the rabbit and the hat. 
Even when the problem is properly identified and a relevant sche-ma is operative, it may be misapplied in any number of inventive ways. First, information may be ignored. If perceived, the perceptions may be faulty. If accurate, they may be misinterpreted. If cor-rectly interpreted, they may be disorganized. If organized, they may be manipulated in a faulty fashion (not at all or too much) by an imagination which is too weak or too strong. Poor language skills can contribute to the formation of sloppy symbols and clumsy concep- tions. Inattentiveness can lead to the confusion of unrelated events; there may be an inability to isolate events which are concurrent but unrelated or the missing connections between apparently unrelated occurences. The behavioral response may not be tested, or it may be poorly tested. It may be illogical, and ergo irrelevant, or too logi-cal, and ergo unappealing).

To supply a concrete example, consider the uncertainty of the credibility of a nuclear threat. Any violence is a confused, uncertain activity, with the extreme of nuclear war all the more unpredictable because decisions are made by fallible people organized into imper-fect governments depending on partial if not faulty communications and are carried out by potential hot-heads whose commitments and reputations can take them to unauthorized excesses. Credibility in such a mechanism qualifies as rational fear of a terrifying disaster.

Unsuccessful behavior is obviously likely to result from any error in any such problem solving process. Mistakes might cancel each other out but more probably compound each other. Of course failure might also result from the influence of unknown factors on those known and understood. More important, lack of success might be due to the fact that the people involved are not even seeking a solution to the given problem. If they perceive a problem as such, they might simply indulge in end-directed analysis, which is a gen-eral cognitive ploy directed more toward finding a gratifying re-sponse rather than the best possible to the situation confronting them. Ultimately, failure is due, as philosopher Lawrence Berra noted, to people making " to many wrong mistakes".

It is crucial to bear in mind that the use of the term "Intelligent" or "Stupid" to describe a problem solver depends on the degree of success or failure perceived: Adolf Hitler made this point when referring the those who tried but failed to assassinate him on July 20, 1944 as "Stupid". In this matter, as in so many others, humans have proved to be biased judges-with our bias being inherent in our schemas, which make us both arbitrary and subjective. To complicate the matter further, there is a fine line between stupid and clever.

Common Sense: If intelligence is a bit too grandiose, let us consider the more pedestrian "Common sense". First, we note Voltaire's pithy observation that common sense is not so com-mon. The explanation for its uncommonness is that it is a compounding of two interactive cognitive principles: objectivity and morality. Our schemas keep us from being objective, and morality is as slippery as a bucket of eels, so it is surprising to find anyone at a given time capable of rendering awesomely brilliant, commonsensical judgments-"Common sense $\mathrm{x}$ intelligence $=\mathrm{k}$ ". (Meaning, you can safely stop reading now.)

Judgements: We judge (i.e., evaluate) human behavior by arbitrarily selected criteria: e.g., a person may be judged a "Suc-cess" accordingto wealth, status, power, health, number of children, etc. The selection of the specific criterion used is culturally predetermined by the judge's background and completely arbitrary (in that two judges sitting side by side may disagree due to their backgrounds) and often irrelevant (i.e., stupid).

The fact that we are so consistently arbitrary has two major impli-cations for the student of stupidity.
Sounding Socratic, the first is that the only thing we can really know about ourselves is that we cannot really know anything about ourselves. Over 100 years of un-biased scientific studies have conclusively demonstrated that we are arbitrary creatures incapable of making unbiased studies, particularly of our own behavior. If you need evidence of our arbitrary nature, review the more than 250 competing and often conflicting theories about human nature which have been proposed by behavioral scientists. Taken together, these indicate only that human behavior is so varied that it can be interpreted according to any number of standards to support any number of causal explanations.

The second major implication of arbitrariness is that it all but guarantees we will be stupid because it inhibits our recognition of what stupid behavior is, especially when we are actively involved in it. One of the few constants about people is that we never interpret our own behavior as stupid. Were we to do so, there would undoubtedly be much less stupidity. However, as judging behavior is such an interpretive process, we tend to favor explanations which confirm our senses ofpride and self-esteem while being loath to admit our idiocy if an alternative explanation can be proffered by ourselves or friends. (Our enemies are probably equally motivated to find fault with us, but neutralbystanders might be objective if indifferent.)

To be more specific, judgment is biased by the existingschema, with arbitrariness and subjectivity contributing to the usually selfconfirming result. First, criteria for judgment are arbitrarily selected, and then, within that context, subjective judgments are made. To continue with the example cited above, a politician would probably judge success by the criterion of power, whereas a financier might judgeby wealth. Of course, wealth lends itself to objective measurement, in that money can be counted, but clever accountants can render financial affairs subjective by a little creative fudging and finagling. Likewise, the "War on Crime" can be judged by different criteria depending on the purpose of the judge: when justifying the existing budget, emphasis is placed on the success of existing law en-forcement programs; on the other hand, when soliciting an in-crease in supporting funds, emphasisis placed on the extent threat of crime in society.

A final consideration in judging stupidity is timing-when the evaluation is made. A case in point was created by post-WWI Russian and Germany who connived to contravene the restrictions of the Versailles Treaty against the Wehrmacht hav-ing tanks in Germany by having the Germans help the Russians build tanks in Russia, which both countries then used for train-ing purposes there. This arrangement continued through the 1920's into the early 1930's. Judged in June, 1941, it was incredibly stupid of Russians to have been party to the deal, but three years later, it was Germans who were adjudged to be the stupider of the erstwhile partners as Russian tanks poured into their country.

In general, whatever stupidity is, it is induced by the biased judgments a person's schema imposes on his experiences and perceptions, as is illustrated by an anecdote about a confrontation between an alcoholic ballplayer and his reform-minded manager. The manager called the player into his office one afternoon and placed an earthworm in a glass of water. The worm wriggled around quite happily until placed in a second glass containing alcohol, whence it promptly shriveled up and died. "See that?" exclaimed the manager. "Sure," replied the player. "If you drink, you won't have worms."

The single, obvious lesson to be drawn here is that there is no single, obvious lesson to be drawn from what we perceive and do. Each person draws his own conclusions to suit himself, and this is where the behaviorists' stimulus-response model fails because what behavior a stimulus induces, for example, is so unpredictable. For example, communal poverty might be per-ceived as a stimulus for programs of economic development or simply something to escape. 
This, in turn, neutralizes Hebb's Rule-that correct decisions rein-force neural pathways -because what is correct is likewise so sub-jective. Although success is a reward and failure is a punishment, just what exactly is being rewarded or punished (and even what con-stitutes success or failure or even what constitutes a reward or pun-ishment) is never quite clear, since we can draw the damndest con-clusions as to what is going on in our perceptual world. For exam-ple, Saddam Hussein perceived the Mother-of-All-Battles (i.e., when he got thrown out of Kuwait in 1991) as a great victory for Iraq. It takes an overwhelmingly unequivocal victory, as in 2003, to win a war of ideas against someone with that kind of mentality. Further, in a general sense, it shows that facts are secondary to myths in influ-encing behavior. Finally, as psychologist Winston Churchill noted, sometimes we are helped (rewarded) by our mistakes and injured (punished) by our successes. An unfortunate, obscure example of this latter principlewas provided by the vilification and demotion of the heroic Australians who saved their country by defeating an advancing Japanese force on the Kokoda Trail on New Guinea in 1942: they were basically overachievers who were underappreciated if not resented by the brass back at HQ for showing them up.

To expand on the point of the subjective nature of rewards and punishments, there may be disagreement if not confusion as to what constitutes good and bad, right and wrong-indeed reality and fanta-sy. For example, in post-Saddam Iraq, there was considerable de-bate as to what was going on, why we were there, what we were do-ing there, what we should have been doing there, how we should goabout it, if we should go about it, etc. So, what was good or bad? Right or wrong?

Usually, the mind shapes perceptions by structuring (according to a given emotional disposition) the ways objects and events are construed and represented. By this manner, experiences commonly teach us lessons which are inherently biased toward the existing schema. As we are inclined to assume credit for anything positive and attribute blame elsewhere for anything negative that occurs around us, we tend to become better adapted to ourselves than to our environment. It is this positive feedback system between our judged actions and beliefs which induces us to persist in self-con- firming behavior which others construe as stupid but which we canand do consider as necessary or intelligent.

In the biased world of arbitrary judgments, it is easy to label an act as "Intelligent" if it can be and is construed as successful. However, the evaluation of a person's mentality according to the results of his behavior can be misleading. Consistent with humanity's tendency to flatter itself, we usually attribute to intelligence significant discoveries simply because they are considered major achievements in the development of civilization. Many of these were really just accidental and in no way due to foresight, planning or directed thinking. No one sat down to plan out how to control fire. America was discovered by Norsemen who could not turn their boats around, Columbus searching for Asia and Frenchmen following the cod. Every step Dalton took to his atomic theory was either logically inconsistent or wrong, and the discovery of penicillin was made pos- sible by sloppy lab technique. As beneficial as these events were, none of them exemplifies intelligence in any way.

Similarly, the term "Stupidity" is often used to indicate a behavioral strategy that failed, although all failures are not necessarily stupid. For example, a failure really does not reflect stupidity if it was due to the influence of unknowable factors. Failure may properly be regarded as stupid when it is caused by the application of an inappropriate schema or the misapplication of an appropriate schema to a problem. (Of course, a compounding occurs when an inappropriate schema is misapplied.) Earlier, we reviewed briefly the mechanical malfunctioning (i.e., ignoring data, misperceiving data, faulty symbolizing, etc.) which can contribute to maladaptive behavior.
However, our most profound interest is not in the incidental breakdown of relevant schemas but in the deleterious nature of the social psyche which tends to make all belief systems and their behavi-oral sets maladapted to each other and the environment.

Logic: Although the labels "Intelligence" and "Stupidity" are easy to apply in everyday life, efforts to elucidate the underlying schematic process have yielded little but confusion for centuries on end. Perhaps it is time to consider the possibility that something is wrong if not with the questions being asked then with the questioners asking them. One obvious problem is that the questioners have human minds, which means that analysis tends to be both linear and biased. When using words, as most of us do, people can think of, at most, only one thing at atime. This is the source of logic-thinking in ordered steps, and it puts us at a disadvantage when trying to understand the complexities of nature. Of course, our triumphs in unraveling the secrets of the physical universe have been possible because we can hold all other conditions constant while we selectively alter one vari-able at a time and observe dependent reactions. However, this approach is clearly of limited value in the study of the living world, in which the dynamic interdependence of systems is really the proper subject for investigation. On the other hand, when we use mathematical symbols rather than words to facili- tate complex, computerized thought, the resultant models fail to reflect the entirety of the human condition because of our inability to quantify social values, psychological vagaries and spiritual intangibles.

We would be most successful in understanding ourselves if we not only asked the right questions correctly but had no predetermined criteria for shaping our answers. Nevertheless, this investigation of how the human mind works will emphasize stupidity. Why stupidity? Because it is ubiquitous! Because it is eternal! Becauseit has been neglected and ignored! Because it is found in overwhelming abundance in every phase and facet of the human experience, except asa topic in psychology texts and journals where it is overwhelming by itsinexplicable but notable absence.

Thus, this will not be a balanced account of human behavior but rather an attempt to redress an existing imbalance. We will consider people not only as problem solvers but as problem creators. We will analyze not only how people succeed but how they fail. We will examine why people do not learn some lessons by favoing some over others. We will examine how human behavior can be simultaneously both adaptive and maladaptive, and our profoundest discovery of all will be that intelligence and stupidity are not opposites but siblings - that they contrast with one another like two faces on a coin. Indeed, a normal, not quite idiot savant may be incredibly intelligent in one way (e.g., math or music) and equally stupid in others (finance or romance): if a specific example serves to make the same point, Bill Clinton was both super smart and super dumb. Put another way, any magician good enough to make the two-faced coin disap-pear knows that the more intelligent a person is, the easier it is to deceive him/her.

Coping?: When people interact with their environment, their be-havior is directed by a schematic cognitive program. A particular act can be construed as "Intelligent" or "Stupid" depending upon the perceived degree of success achieved, but while these labels indicate opposite evaluations, they do not indicate different cerebral programs. Nor should stupidity be viewed as a disruption of an "In-telligence mechanism". There is a coping (or responding) mechanism in action, and it can be construed as stupid and/or intelligent depend-ing upon the circumstances and the judges. This coping mechanism is multidimensional, but we shall focus on three arbitrary/subjective facets important to understanding stupidity - information processing, (mal)adaptation and relevance.

When considering the ways by which the human mind processes information, it is imperative to remember that the normal cognitive state is that of self-deception. 
Our self-deceptive nature tends to make us stupid and, more to the point of our analysis here, certainly complicates the relationship of knowledge to stupidity. If people simply do not have relevant information available to them in a per-ceivable form, they are agnostic. However, if they ignore available information to the impairment of schematic accuracy, they are being self-deceptive and probably stupid. Likewise, if they misinterpret information, they are being "Data dumb", although there may be some social advantage to certain cognitive indiscretions. The person who ignores warnings of an impending disaster exemplifies the con-dition of being data dumb. Military history, particularly, provides a litany of warnings unheeded or misconstrued.

The relationship of knowledge to stupidity is very circumstantial. Usually, the more one knows about a situation, themore successful his behavior is likely to be, but there is cer-tainly no advantage in being overloaded with useless information. Worse yet, a person may worry himself sick if he is un-fortunate enough to know about a threatening situation over which he has no influence whatsoever. Thus, having knowledge can be maladaptive, particularly if one has no coping response available.

If the relationship between stupidity and knowledge is mostly circumstantial, that between stupidity and ignorance is usually reciprocal. Ignorance often exists because a schema blocks relevant learning. On the other hand, stupidity may keep people ignorant by inhibiting behavior which would allow corrective, adaptive learning. Instead, a positive feedback system may then make behavior increasingly maladaptive to the immediate environment.

Data processing systems are most maladaptive when they make dysfunctional associations among bits of information. Stupidity is thus made more likely when there is not enough information (a party is to some degree uninformed), when there is too much (overloaded) but most commonly when it is wrong (misinformed). Stupidity also results when information that is present and correct is misemphasized or misinterpreted. Of course, more profound kinds of stupidity are produced from a complexing of different possible source errors- e.g., a misinformed person misinterpreting inaccurate data. Finally, the process becomes blatantly unethical when a person deliberately cherry picks facts from an ambiguous field of data to rationalize a predetermined course of action.

Just as many factors related to information processing may ren-der a schema maladaptive, so is the determination of "Maladaptation" another very arbitrary/subjective facet of the general coping mechanism of the mind. For example, although a person may know his drug addiction is maladaptive over the long haul, getting the next fix is most compelling and in his immediate, short-term best interest. While it may be to a company's advantage to control more than a fair share of resources, this may be maladaptive for its supporting culture. Since determining maladaptivity depends so much on the arbitrary selection of the referent time scale and the standards and perspectives for judgment as well as the subjective evaluations of the judges, it, like "Knowing", turns out to be a rather imprecise guide for determining whether or not an act is to be deemed stupid.

When attempting to determine whether an act is adaptive or maladaptive, subjective judgments may be predetermined by the arbitrary selection of the referent itself. Is behavior maladaptive for an individual? His reference group? The environment? Behavior can be maladaptive relative to any or all of these referents. A human system virtually by definition is internally inconsistent and maladapted toitself. It can pointedly disrupt communication and adjustment to other human systems, and it can prevent accurate feedback from the environment, to the long-term detriment of the capacity of nature to sustain the human experiment.
In this context and as a refutation of the theory of cognitive dissonance (cogdis), Adolf Hitler was a case study in stupidity in that the more his belief in Providence (i.e., God) was contradicted by facts from his environment, the stronger he embraced it -clearly a road map for a disastrous one-way, dead-end street.

Cognitive dissonance is defined as an uncomfortable condition resulting from holding contradictory beliefs. Obviously, stupidity helps in this process, in that the dumber a person is, the easierit is for her to hold contradictory beliefs. For us, we expand cogdis to cover the condition of a deeply held belief at odds with relevant be- havior as in Crusaders who killed for Christ or a corrupt cop. In addi- tion, we extend the principle beyond the individual to society in gen- eral, in that we find a culture may profess a belief which is contra-dictedby the conduct of its members, as when the institution of sci-ence is set up to protect errant members rather than correct thier er-rors.

While it is reasonable to presume that a such dissonancecreates a psychic tension which humans ache to resolve, this commonly is not the case: people simply live with their contra-dictions. As Walt Whitman observed, "Do I contradict myself? Very well then. I contradict myself." This is not much of a stretch, since one can posit that a behavioral system is an ex-pression of an underlying belief system-so you have a behavioral belief system at odds with a theoretical/ethical belief sys-tem. The expected dissonance is common mitigated by word games, which reduce cognitive tension by redefining everything to suit the super-ego individual and society. The oddity is that people then get upset when confronted by some aggravating person who, like the honest cop, presumes to act according to the explicit verbal creed and challenges the society to adapt to her, live up to itselfor admit its basic ethic is a not particularly amusing self-inflicted joke.

Generally, in any situation, there are three concentric fields for behavioral adaptation. The first is an individual system-a person, business group, team, etc. The next is the social context of the supporting culture-other individuals and groups. Final-ly, there is the ultimate arbiter of fitness - the physical environment. An intelligentpolicy is one which is advantageous to the performer, beneficial to humanity in general and at least not detrimental to the environment. Thedevelopment of the telephone might serve as an example of an invention which was a success all three ways. Mr. Bell and his fam-ily prospered; society was provided with speedier communication; and,except for some unsightly wires, no major negative impact on the environment was suffered. Usually, of course, a policy engenders new problems as it solves the old by emphasizing success in the first, limitedcategory at the expense of the others.

Thus can a policy be both adaptive and maladaptive. In a short time span, a pattern of behavior can be construed as adaptive by those who profit from it while it is condemned by those who must endure it. Over a longer time span, individuals may alter their judgments about a policy as they become aware of unexpected and clearly negative results. As a bottom line, "Self-interest" is really the final criterion of judgment, and stupidity is behavior counter-productive to the welfare of the performer. As the Shah of Iran, Ferdinand Marcos of the Philippines and Nicolae Ceausescu of Romania found, the immediate pursuit of one's own best interest may be, in the long run, $\mathrm{n}$ - doxically maladaptive in the extreme.

The American industrial complex is a prime example of a dynamic association of similar organizations concentrating on their own short-term enhancement while contributing to the demise of the common life support system for general society. The government's response to the pollution and exploitation of our natural resources was the Environmental Protection Agency. On non-recycled paper, it was anideal solution to a real problem. In reality, it was taken over by the industries it was designed to control. 
Its record in promoting pollution and the desecration of nature is unsurpassed in the annals of gov-ernment. It is most easily dismissed as a misnomer: it should be called the Industrial Protection Agency or the Environmental Pollution Agency.

If it is difficult to generalize about and define maladaptation, it may be quite easy to recognize. Commonly, a behavioral trend goes to a self-defeating excess. Technological overde-velopment, political repression and human exploitation are all examples of maladaptation induced by the inherent tendency of cultures to function as positive feedback systems. Such ex-cesses usually indicate a power structure caught up in the neurotic paradox: excesses are promoted as entrenched values both reinforce established patterns of behavior and render criticism less likely and less effective. In most cases, a dominant subgroup controls its supporting culture and may be living beyond the carrying capacity of the general society.

Maladaptation usually indicates that the coping mechanism really is not "Coping" but is rather simply responding in counter productive ways. In a more common but less spectacular fash-ion, nonadaptive behavior indicates that the coping mechanism is responding in wasteful, irrelevant (i.e., stupid) ways. As indicatedabove, the determination of relevance/irrelevance requires both arbitrary decisions and subjective judgments. The arbitrary criteria by which relevance may be subjectively judged are: context, personnel (the people who act/judge) and purpose.

The context of an object or behavior does much to determine -indeed, it practically defines - just what its relevance is. With regard to an object, as primatologist Winston S. Churchill ob-served: "A baboon in a forest is a matter of legitimate speculation; a baboon in a zoo is an object of public curiosity; but a baboon in your wife's bed is a cause of the gravest concern." As with baboons, so with behavior. Thus, the purpose of a doctor asking, "How are you?" may vary with the setting. In his office, it is likely a professional inquiry: on thestreet, it is probably a cultural throw-away.

Of course, context is not merely a matter of physical location. Behavior is invariably interpreted in a conceptual context, butit is the observer who arbitrarily selects the context in which relevance is judged. Thus, a patriotic hawk construes a Con-gressional vote for a large defense budget as laudable, whereas a frugal-minded economist would regard the same act as fiscal madness. The one views the purchase of vast amounts of military hardware and the maintenance of a sizable military force as necessary for national security; the other considers the money spent as an intolerable drain on our financial resources. Likewise, in legal affairs, the context may determine the legality of an act: exercises in freedom of speech in peacetime may be regarded as seditiously criminal in wartime.

In a similar way, arbitrary personal considerations play a major role in evaluating the relevance of behavior. The critical factor is the relationship between the actor and the observer. If a friend and an enemy do the same thing, two different in-terpretations are likely.In terms of the example just cited, a political ally voting for a large defense budget is patriotic, whereas an opponent doing so is a reckless spendthrift. Likewise, when a member of one's political party violates security by leaking evidence of official corruption, it is an act of courage; when a member of the opposition does so, it is a breach of security. (When a no-account enlisted man in the armed for-ces doesit, it is a crime.)

In addition to the three elements of subjectivity just considered, there is "Timing"-in the sense that for information processing to be helpful, it must be accomplished within a given time frame: the military call it "Actionable intelligence". This consideration is complicated by the fact that there is a built-in lag in all data processing so some delay has to be accepted as a given.
This might be measured in nanoseconds in the cases of computers, milliseconds in very sharp human minds or years in behaviorists, but there is some delay between perception and comprehension. If the delay is so short that adaptation is im-possible, then the issue of stupidity does not arise. However, it is at best sad when one realizes too late what the available data "Really meant", and what one should have done.

To carry this a step further, there can be a stupidity lag between the moment one realizes what should be done and the time of action. If action is both timely and proper, it probably is successful. How-ever, if it is delayed too long, even the correct response may be stupid. For an individual, the time scale might be measured in sec-onds while for nations, it might be years: as H. G. Wells observed, the English rely on a time lag of about 75 years between the per-ception that something should be done about a problem and a serious attempt to do it.

To confuse matters more, in times of decision while under psychological duress, meanings of words may change. This malaise afflicted Athens during the Peloponnesian War (431-404 B.C.) when reckless audacity in an ally became courage; prudent hesitation was cowardice; moderation was unmanly whereas frantic violence was the Greek equivalent of macho; and the liberal ability to see all sides of an issue was equated with the Hamletesque inability to act at all.

Not only does thinking become muddled in such circumstances, but there is also a cultural loss when attention afforded an innovation and its considered worth (relevance) are both only secondarily determined by its inherent worth. The status of the innovator may either add to or detract from the value an offering is accorded. This social dimension is a major determinant in groupthink: e.g., when a re-spected leader sponsors a proposition, it is likely to receive a favora-ble reaction from his followers.

The final criterion by which relevance is judged is that of purpose. Survival is a basic purpose of life, but when it becomes an end in itself, development ceases and is replaced by stagnation. When the purpose is simply to survive, human behavior is shaped by an opportunistic schema which is con-sistent only in the ease with which it yields to immediate cir-cumstances. In such cases, life is a struggle for short-term ex-istence, with no consideration for long-term ramifications of behavior. Such a schema might be labeled "Meism/ Nowism" as any other morality is an unaffordable luxury.

If behavior is not dictated by necessity, purpose can be cre- ated by a commitment to group norms. Accepting group stan-dards can be stupid in that it defines adjustment in terms of a single, totally arbitrary value system. In general, most schemas are directed toward maintaining a status quo. Unfortunately, they may be so committed to themselves that they self-destruct. The process begins when an initially successful pattern of behavior becomes routine; when it serves to block innovation, it promotes failure. Reformers who then call for improvements in the schema are regarded as a source of distress. They are usually considered maladjusted and are not, in fact, adjusted to the cultural values society has enshrined as sacred. This par-ticular kind of vexation is a growing problem today, as Western Civilization moves from making people equal in rights to similar in thought and behavior.

Finally, judgment may be complicated by the application of different schemas by different people to the same data. This occurred in November of 1983 when events surrounding a NATO exercise led to a threat of the Cold War turning hot. One of the problems was that the West viewed events in the context of Munich, 1938, when appeasement led eventually to war while the Soviets viewed the same events in the context of the German invasion of Russia in 1941, when they were caught off guard. This was a very real case of the application of dif- ferent schemas leading to a very tense situation but fortunately nothing more, although matters were further complicated by President Reagan's disturbing personal belief that the confluence of events presaged Biblical Armageddon. 
Benefits: In a more positive vein, we may derive some psychosocial benefits from the arbitrary and subjective ways we misinterpret our behavior. We commonly indulge ourselves by holding self-serving, inconsistent, unrealistic beliefs which characteristically contradict our behavior. With such cognitive dissonant aids, people can live in mental worlds which transcend reality and, to the extent that some healthy fantasies are realized, improve their material circumstances. Such cerebral boot-strapping is common in humans and provides support for the coping mechanism which can also be simultaneously so helpful and maladaptive.

For better and worse, the normal human mentality protects us from ourselves so that we cannot recognize the irrationality of our belief systems nor the inconsistencies between them and our behavior. What kind of inconsistencies? We are rewarded for lying and cheat- ing, although our superego value system tells us we should be fair and honest. We are advised to be meek and humble by the powerful and mighty. A person really could be justly accused of being stupid just for doing as he is told. Usually, most people are street wise enough to resolve such paradoxes pragmatically by seeking tangible rewards and leaving ethical considerations to the empty-handed.

Characterization: Although recognizing stupidity is a very arbitrary/subjective process, it should be easy to cite the conditions which characterize stupid behavior. Stupidity is commonly considered possible only when and where courses of behavior are optional. If conditions have deteriorated to the extreme point that only a maladaptive act is available, stupidity is no longer the issue. However, it may have been stupid to have become boxed in in the first place.

On the other hand, it is just as stupid (in the sense of being wasteful) to under reach one's level of competence as to overreach it. In the first case, a system fails to develop its potential because it really is not challenged and therefore is not functioning as efficiently as it might. In the second case, stupidity can lead people into an environment or situation in which they cannot function effectively because their behavioral options are unsuited to the conditions at hand. In such a situation, an overambitious system finds itself unable to copewith the problems confronting it. Life's best compromise of competence is to find an environment in which a decent level of efficiency can be sustained over a long period of time, with a reserve capacity available for coping with emergencies.

Another condition thought to characterize stupidity is "Counter-productivity". A stupid schema promotes its own demise by directing its devotees to behave in ways "Perceivably" in their own worst interest. If this is a valid point, how do we explain that such behavior is so common? Nations sleep while their enemies march: on the other hand, paranoids defend themselves in the face of nothing. Companies squander millions on an executive's pet project while rejecting products or improvements which would net them millions and more. The explanation is that stupidity is perceivable as such by all but those engaged in it at the time. These simply cannot perceive their own behavior as stupid because it does not appear to be so in terms of their own schema.

Morality: While failing to perceive their own behavior as stupid, people usually do see themselves as morally justified as they pursue their worst interests. A sense of morality is a human universal, with the many cultures differing only as to the specifics of their various ethical codes. Further, in each and every case, language plays a major role in determining the standards available for evaluating the mor-ality of behavior.

In an absolute sense, there is, unfortunately for all the world's Pollyannas, no simple and direct correlation between success and any one system of (im)morality. Any trite generalization in this re-gard would have too many exceptions to be of any real value.
At best, it might be said that an honest person puts himself at a shortterm disadvantage when dealing with liars, cheats and frauds. These, on the other hand, run the risk of finding their nefarious successes hurt them in the long run.

Thus, stupidity can be viewed as a short-term adaptive mechanism that allows a degree of adaptability denied any strictly rational behavioral system, if indeed any such thing ever existed. To theex-tent that schematic rigidity inhibits the adoption of corrective meas- ures to reduce the causes of existing problems, a system runs the risk of breaking rather than bending. Every living system is going to experience a certain amount of stress; it is in danger when behav-ior becomes increasingly maladaptive as stress increases. This oc-curswhen the schema ceases to be a guide for successful coping with the environment, establishing itself instead as a stumbling block to functional, positive responses. In such situations, new stimuli may elicitan outmoded reaction pattern or perhaps none at all. When a schema finally does break down under stress, even consistent stimuli may elicit chaotic, maladaptive responses.

Contributing Factors: In searching for intrinsic causes of human imperfections, it is most reasonable to begin with a consideration of genetics, and indeed a genetic model for maladaptation has been proposed by evolutionary psychologists Cosmides and Tooby (1987). They attribute some maladaptation to a mismatch between the man- dates of a human gene pool shaped during the Pleistocene but ex- pressed in a modern, urban environment. For example, they allege some digestive maladies and emotional problems are due to the fact that we evolved in and for an age of hunting and gathering. Although they donot specify whether they are considering normal, abnormal or vestigial human behavior, they suggest a phylogenetic model which explains some maladaptive human behavior in terms of the time lag between an evolving genome and the constantly changing social/intellectual environment. Another example has been described by psychologists Nueberg and Cottrell (2005), who posit that bias toward out-groups wasof survival advantage in the past, when others often were a threat, but creates friction now in cosmopolitan, diversified cultures.

Although stupidity is a behavioral universal, this cannot be taken as proof of a genetic basis for the trait, as it could be the legacy of a common culture or, more probably, a function inherent in lan- guage. Most emphatically, stupidity is not mental retardation, which is caused by the many factors which limit the cognitive skills of those whotest poorly on conventional IQ tests. Such factors may be genetic or chemical, as in the cas-es of drugs (alcohol) or poisons (sodium floride

). Retardation may also be caused by head injuries at birth or otherwise and infections. According to the Chinese, a baby's intellect is compromised if the afterbirth is eaten by dogs or swine. However, all such restrictions on the development of normal mental functions (along with the infirmities of old age ) are irrelevant to the topic at hand. Stupidity is not a restricted form of intelligence but a normal mental function in its own right and an expression of our cultural not our genetic heritage. Or, as comic Bertrand Russell put it, "Men are born ignorant, not stupid; they are made stupid by education" or failure thereof.

Education aside, there are any number of environmental factors which promote maladaptive behavior, but they really do not contribute directly to stupidity, as caused by an irrelevant schema. Some of the environmental factors which reduce adaptability are climate, diet and disease. In addition, other factors, like fatigue, age and drugs may play roles as well. It is interesting to note that all the above factors hit the smartest hardest. The dull may get a bit duller, but the brilliant can suffer greatly. Thus, society loses not only by a drop in general re-sponsiveness of everyone but particularly from the loss of themost helpful, creative ideas from the very bright. In these ways such factors foster general stupidity. 
Geography, for example, can play an indirect role in the development of stupidity. Usually, seacoasts are areas of cultural interaction. Where transportation is difficult, as in the mountains, or where distances are forbidding, as on the plains, beliefs are less likely to be challenged and become more firmly entrenched. Of course, in a constant environment, fixed beliefs may be quite functional for the long haul, but when change does come, adaptation is then all the more difficult.

Climate has a more direct role in effecting stupidity. The oppressive heat and humidity in the Middle East and much of India no doubt played a role in the development of the fatalistic indigenous religions. An accepting, passive life style is adaptive to such stultifying and sultry conditions in that it keeps one from overheating, but ithardly encourages inventive enterprise. The tropics are disease ridden and stupefying in that they afford too much food and comfort naturallyand provide too little stimulus for people to develop their potential.

By way of contrast, the moderate and varying climates of the temperate zones encourage people to interact vigorously with the environment as they make continual adjustments to changing seasons. In the past, for much of the year, work was a way to keep warm, so the climate encouraged an active work ethic. As working is a way of learning, a culture actively engaged with the environment tends to thwart the development of stupidity-e.g., the climate of New England challenged those living there to respond positively.

On the other hand, the harsher the environment, the more stupidity is promoted, in that one cannot afford to be too sensitive to the rigors of his surroundings. Thus, insensitivity to the point of callousness can be an advantage, with the hypersensitive sometimes breaking down under demanding climatic and work induced stress duller compatriots may hardly, if at all, perceive.

As if cultural stupidity is not enough, people have a tradition of stupefying themselves artificially to help them escape self-imposed stress. While there are reports of birds, elephants and monkeys selectively eating fermented fruit (presumably for the effect), people drug themselves en masse. Alcohol is one of our milder stupefiers and may have made civilization both necessary and possible. The standard saw is that nomads settled down to cultivate grain for food, but an alternative explanation is that they grew grain for the production of alcoholic beverages. The psychological escape afforded by such from the long -term stress of concentrated associations of town life may have facilitated the development of civilization.

Even without artificial stupefiers like alcohol and narcotics to help them, people routinely achieve irrelevance by adhering to or seeking out a maladaptive schema. When indulging in such stupidity, they usually display certain symptoms characteristic of their condition. As mentioned above, ignorance commonly enjoys a reciprocal association with stupidity: this can take the form of a positive feedback system in which ignorance begets stupidity which begets further ignorance. Other symptoms of stupidity are often opposite extremes bracketing func-tional means. Stupidity can be due to as well as cause both in-sensitivity and hypersensitivity. If confusion is a stupid state, clarity in the expression of trenchant thought can be offensive and thus stupidly disrupt social coordination and cooperation. It may be equally stupid for a person to be either too slow or too fast in reacting to a situation. A stupid person might be too fanatical or not determined enough; indifferent or too rigid; overbearing or too casual; ignorant of details or drowned in in-formation; cowardly or too heroic; too far ahead or way behind the times.

However, under extreme conditions, any of the normally stupid extremes may be the operational ideal. Sometimes, we must be fast, callous, reckless or otherwise intemperate. Judging when conditions are abnormal enough to require the abnormal response is one of the ultimate subjective tests anyone can face.
In such a situation, the standard rules no longer apply and emergency measures must be adopted if the system (individual or reference group) is to survive. Whatever the conditions, stupidity is the failure to apply the appro-priate schema effectively when needed.

While considering extremes, it is noteworthy that humans are extreme in their cultivation of stupidity. It is found in the animal world but is limited in both degree and kind. In more general terms, some students of human nature aver that there is nothing qualitatively distinctive about our species: according to this view, we are just a particular blend of many traits com-monly found, although in different proportions, in animals. Our nutritional needs, bodily functions and behavioral habits are all considered typically animal - perhaps extreme in some cases, as with learning, aggression and stupidity-but not distinct in kind from our fellow creatures.

An alternate view is that we are indeed distinctive. Just what the distinction is has long been a subject of speculation. The "Soul" is one of the longest-lived attributes which is alleged to separate us from beasts which seldom kill their own kind and never en masse. More notably, language is thought to be a distinguishing human characteristic, and it isas long as it is defined as the way humans communicate. Stupidity happens to be one of those many types of behavior which we share with our relatives. We have just perfected it and, thanks to language, given it a distinctly human twist.

Animal Stupidity: The common feature in all cases of stupidity is that a given program of response blocks a more relevant reaction, and any individual which challenges reality may pay the ultimate price for departing from the truth. In insects, the program may be very limited and keyed tightly to a few critical environmental stimuli. Differences may appear among the caste groups of social insects like bees-workerswork, drones drone, etc. - but, within each caste there is no individual variation whatsoever.

The nest building behavior of the digger wasp provides a classic example of the inability of an animal behavioral system to adjust to altered conditions. The usual routine of the female is to dig a nest, kill some form of prey, drag the victim to the nest, place it in the nest, lay eggs on it (the larvae from which will feed on the carcass after the eggs hatch) and then close the nest. This sequence might be considered the insect's schema for action, and it is usually quite effective, as long asthere is no scientist around to play God. In the event of divine inter- vention with any step in the ritual, the rest of the behavioral program will be continued blindly, although it has been ren-dered pointless. If, for example, the prey is removed from the nest after the eggs have been laid but before it is sealed, it will be sealed anyway, dooming the offspring to a tragedy of larval dimensions. The only reason this is not considered a clas-sic example of stupidity is that the wasp has no choicein the matter. It is preprogrammed to follow a set pattern of behavior, with no adjustment to information feeding back from the environment. Once the schema starts the sequence of action, it runs to completion.

In contrast to the rigid, preprogrammed nature of insect behavior, vertebrates are characterized by an open genetic pro-gram. The responses of adults of a species will thus be similar to the degree that they share similar genes and experiences and different to the degreethat the general patterns of behavior are shaped by unique experiencesof each individual. While higher vertebrates can be individualistic, social behavior of verte-brates in general has been promoted and achieved by 1.) en-riched communication systems, 2.) precision in recognizing and responding to individual groupmates by the learning of idiosyncratic behaviors, and 3.) the formation of subgroups within the general society. Usually, vertebrate behavior favors individual and in- group survival at the expense of the overall, extended society.

It is important to note that the process of learning, which is so crucial to the vertebrate way of life, is preconditioned in many species by a biological disposition to learn actions that are crucial to survival. 
This is the phenomenon of "Preparedness" and is exemplified by the facility with which birds learn to fly and people learn to speak. It suggests that organisms may be preprogrammed neurologically to learn certain behaviors as part of their normal developmental process.

While "Preparedness" indicates a positive legacy from an organism's evolutionary past, the Garcia Effect demonstrates that there are biological predispositions in some species to favor the learning of certain lessons over others in the lab. The aver-age pigeon will learn to peck a disc to obtain food but will not learn to peck a disc to avoid a shock. For a rat, the same learn-ing pattern is found: it can learn to press a bar to obtain food but cannot learn to press a bar to avoid a shock. "Preparedness" and the Garcia Effect suggest that learning can be promoted and inhibited by a preprogrammed mental set in an or- ganism. This is the effect of the experience-based schema on humans: it makes the future learning of certain things easier and that of others more difficult.

The interference of learning with adaptation through further learning is not a uniquely human problem. It is found, for example, among earth worms, which can be trained to turn away from an "Electrode alley" in a T-box - an experimental construct in which the animal reaches a choice-point and must go to one side or the other. Having learned to avoid the side with the electrode, a given worm will at first have difficulty learning to turn the other way when the electrode is switched to the pre-viously "Correct" side. In this case, what the animal had learned clearly interfered with its ability to adjust to altered environmental conditions, as it had to overcome the original lesson before it could form a new, effective schema.

Among both insects and birds, mimicry is perpetrated on unwitting hosts which have difficulty learning to discriminate be-tween their own kind and impostors. Limitations on the ability of some social insects to learn make them perfect hosts for in-quilines-parasites that are dependent throughout their life cycle on their hosts. These penetrate the alien society by means of physiological and behavioral mechanisms which have developed, through convergent evolution, the identifying traits of the host species. Thus, they are accepted because they provide the few key stimuli their hosts recognize as defining membership in the group.

Of course, the failure of the hosts to reject the invadersmight be due more to a genetic limitation on their ability to perceive and learn than to a purely learned inability to learn. Although some animals and humans cannot learn certain things, they are not necessarily, ipso facto stupid. The range of their biological programsto react to environmental contingencies is somehow restricted, be it due to genetics, learning or any compounded combination ofphylogenetic and ontological factors. Thus, while genetics may limit such organisms' abilities to learn, that does not qualify as stupidity ac- cording to our definition of a "learned inability to learn".

Since vertebrates have more streams of information by which they can check phonies than do insects, most do not usually hostmimics. Some birds, however, are victimized by parasitic mimicry of their eggs. For example, cowbird eggs are tailored not only to a particular host species but to their own local population. Among host species, there is considerable variation in tolerance to cowbird eggs, with "Discriminator" populations rejecting any cowbird egg that is not closely mimetic and "Non-discriminator" populations accepting eggs of various sizes, colors and patterns. In a general sense, the mammalian learning "Strategy", if you will, is more open than the more structured and intrinsically limited learning fields of other classes of organisms like insects. Certainly, the learning process (witha price sometimes paid for learning) in mammals is directed more by experience with the environment than by a tight genetic program and thus usually promotes adaptation to short-term changes in their immediate surroundings.
Still, this is not always the case. In water-shrews, for example, learning can lead to some bizarre results. These creatures certainly challenge the basic principle that learning is adaptive because their distinctive behavioral characteristic is the inflexible tenacity with which they cling to any habit once formed. It might be said that learning would be adaptive if it continued and thus permitted continual adjustments to changing conditions, but in this regard, water-shrews are archetypically stupid. Once one has learned a pathway through its environment, it will persist in its locomotor pattern although the path may have been altered significantly. (E.g., if it learned to jump on a stone at a certain point, it will continue to jump there even if the stone is removed.) Thus, the shrew disregards its senses when it encounters an alteration of theenvironment which cries out for an alteration in behavior. Once a habit is ingrained, it inhibits the acquisition of more and better knowledge- i.e., a better schema. This dominance of an established motor pattern over learning is a striking peculiarity of the water-shrew, whereas the shaping of learning by cognitive habit is more common among the moreintelligent mammals.

Outside the lab, animals of all kinds may be fooled by mimicry and deceitful displays of members of their own and other species. As mentioned above, birds may be tricked into playing hosts to the eggs (which usually look something like their own) and young of the scores of brood parasites which infest the avian world. In the case ofthe cuckoo, the hosts end up rearing the parasites' young to the exclusion of their own.

Beyond showing the ability to cope more or less successfully with reality, higher vertebrates evince the cognitive capacity to live in a world of conjured fantasy. This was presumably demonstrated experimentally by B.F. Skinner's "Superstitious pigeons" which came to make idiosyncratic jerking movements in response to randomly scheduled food reinforcement, behaving as if their actions caused the production of food. Likewise, the "Rain dance" of Jane Goodall's chimpanzees suggests a mental ability to associate effects with noncauses. Of course, in this case as well, the behavior does not necessarily indicate the cognitive world of the performers. The animals may be displaying emotion and releasing tension without pre-suming to influence that son-of-a-baboon in the sky who makes it rain. However, it is reasonable to assert that such behavior indicates learning in mammals can carry maladaptation to levels of confusion suggesting stupidity. Indeed, in Wolfgang Köhler's classic The Mentality of Apes (1959), he reported "Crude stupidities arising from habit" in chimp behavior.

In general, the mammalian life style emphasizes extended learning in fewer, slower developing individuals in contrast to more rigid behavior patterns in swarms or schools of quicker developing insects or fish. This necessarily means there is a premium on the adaptability of the individual in times of crisis, rather than a reliance on numbers to carry the species through. However reliable they may usually be, the patterns of behavior which are learned in the routine of daily life may be maladaptive in a short-term emergency situation or when extended unnecessarily to excess as in compulsive grooming habits of some birds and dogs. Adjustment of behavior to novel necessity is a learned process typical of the more adaptable mammals, like our fellow primates and particularly ourselves.

Evolution: As with all of our other special traits, human stu-pidity is the culmination of a long train of development shaped by our evolutionary past, but meaningful generalizations about our psychic evolution are difficult because we are a compro-mise of all the incongruities of life. For example, our ancestors had to be adaptable but not too adaptable. They had to be calm, accepting, thick-skinned and slow-witted to survive the harshness and boredom of daily routine. In contrast to this long-term disposition, they had to be responsive to emergencies and ready to adjust quickly when circum-stances demanded a speedy and novel reaction. 
This basic duality of a long-term/conservative, short-term/innovative mentality made each step in cultural adaptation a gamble at, as it rarely was clear at the time if conditions warranted a new policy to deal with the problem at hand or if staying with the old, tried-and-true way would be adequate to the extent circumstances.

If balance was the key to survival with the less intelligent eliminated, it was a balance of extreme potentials subjectively applied to naturally and culturally selecting conditions: e.g., sensitivity to environmental stimuli is necessary for survival, but either extreme (i.e., hypo/hypersensitivity) can cause a stupid response. Ignorance provides a basis for stupidity in that what we do not know can indeed hurt us, so one measure of stupidity is what we fail to absorb - what we fail to perceive, refuse to learn or omit from reckoning because it conflicts with our self-sustaining schema.

At the same time and in the same way, insensitivity eased the way, for what we do not know cannot worry us. For example, insensitivity toward killing, blood and suffering was of survival advantage in our not so distant past. To the extent that fighting and killing determined survival, brutality was a necessity and sympathy a luxury. Further, to the extent that people were inured to suffering, suffering was an acceptable way of life and death. Thus, the power of dullness made our last million years such a struggle and contributed to our acceptance of our struggling condition.

However, with the mean of sensitivity as the balanced ideal, those who reacted to cold, hunger, abuse and injustice died out. Those who were insensitive to such conditions endured and transmitted their passivity to their descendants. This selective pressure was somewhat balanced by the simultaneous elimination of those insensitive to immediate threats and dan-gers. Thus, the human psyche was shaped for long-term tol-erance of difficult conditions while being responsive to immediate short-term challenges.

Hence, there may really be nothing unique about human stupidity. According to one view, we are, in this regard, only quantitatively but not qualitatively different from our fellow creatures. That is, we are not just as stupid as other animals but more so. In fact, we are quantitatively excessive in one basic psychological capacity relating to stupidity, and that is the ability to learn. We have developed this ability we share with so many species to such an extent that we arein this respect biological extremes.

Neanderthals carried hidebound stupidity based upon on hand signals as far as it could go, leaving modern humans to build on that and while developing inventive stupidity dependent a brain builtto promote foresight, planning and verbal language. With our excessive and exceptional imagination apparently the only limit on ourcapacity to conjure up lessons, we seem to be able to learn anything at all-whether it makes sense or not. Ironically, the power of the human mind to invent supernatural explanations for natural events is matched only by our curious inability to couple the simplest cause-effect relationships. The current worldwide need for birth control is but one handy ex-ample of this latter phenomenon: The inability of civilizationto face up to this matter officially and do something effective about itis just typical of the stupid way people have failed to deal with problems throughout history.

Thus, we may be something other than just excessivelystupid animals. According to a second view of human evolution, the new element in the human equation which makes human stupidity and indeed humans qualitatively unique is language. As we have noted, it is language which intensifies group iden-tification, promotes selfdeception and limits our ability to cope with ourselves. History shows a dreary succession of civilizations arising, growing, flowering and dying with each failure being displaced by another while the method of failure appar-ently remains remarkably constant biased value judgments dis-rupt interaction with the cultural and natural environments until the establishment collapses and is replaced by a new but equally biased system. Most of the time, leaders could not cope with their most fundamental problems because they did not even recognize them as such. The thesis presented here is that they did not do so primarily because of the way language shaped their schemas and defined their perceivable world.

If we owe our general humanity (i.e., our propensity to err) to verbalization, we owe our specific identity to socialization - the learning process which trains us to fit into a particular way of life. In this regard, human societies have two basic problems: 1.) people who fail to fit into the established organi-zation, and 2.) established organizations which fail to reor-ganize according to changing needs of people in a changing world. In both cases, stupidity usually plays a defining if not decisive role.

Considering the evolutionary pressure in favor of success, bright people and efficient organizations should have survival advantages over others. If this is true (and perhaps it is not, as the standards for measuring brilliance and efficiency are not at alwaysclearly defined), the question that must be asked is: How is it that we still have as much stupidity in the world as we do today? There are two obvious answers: Nature and nur-ture: We both breed and cultivate stupidity.

Genetically and culturally, there has always been a tendency of groups to sacrifice quality in favor of the cooperative spirit and group cohesion. Since humans evolved in social groups rather than as individuals, cooperation of members within a group and of groups with each other was (and remains -sometimes) essential. If intel-lectual life was compromised in the cause of cooperation, then it was because the net effect was advantageous for society if not the bewildered individual who, if he is not too stupid, wonders what is going on.

There are two amazing things about the evolution of civilizations. One is the great variety of them which have developed, if not flour-ished: Almost any kind of cultural system can exist at least for a while if it can maintain a minimal, functional level of internal consistency and military strength. The other is that the vast majority of these failed from internal or external competition. Ironically, fail-ure from both causes can be attributed to the fact that culture is an N-dox, positive feedback system, with each civilization lacking in-ternal checkson its own development. Thus, collapse occurs when a culture becomes 1.) fatally inconsistent with itself, 2.) consistent to the point of rigidityor 3.) eliminated through intragroup conflict with competing systems.

On the other hand, a cultural movement may flourish if such competition is balanced as they tend to be in large systems. For example, in 20th century America, labor checked business, and both prospered and promoted Americanism. Nationalistic ambitions in turn are usually checked by those of other countries. Thus, biocultural life seems to follow its own version of Newton's Third Law - every force begetting an equal but op-posite force. If this is true of human affairs, a certain amount of confrontation if not conflict is inherent, necessary andper-haps (if nonviolent) even healthy and good. Indeed, one might say internal conflict is the eternal, self-correcting mechanism of civilization.

In fact, we are biological anomalies in that we have largely replaced interspecific competition with intraspecific (i.e., cultural) competition. As a result, there is no other species we need to fear as much as ourselves. The major question facing us to-day is whether the pattern of replacing one human cultural variation with another will continue. If it does, we might despair over the passing of a particular cultural group, especially if it happens to be our own. How-ever, if it does not, it will not for one of two reasons: Either we will eliminate all cultural life completely, or we will find a healthy, happy way to live with ourselves. 
There has long been a hope that scholarly research would help us learn about ourselves so that we could find a way to live together. Indeed there have been many efforts made to identify adefinitive form of behavior - a uniquely human uni-versal — which would provide a basis for understanding human nature, but so far, the best we have come up with is language, which we define as the way humans communicate. Piles of amassed data show no uniquely human,non-lingual, behavioral constant across cultures. If anything, humans display endless variations in the ways they deal with and discuss basic biological problems (e.g., raising young, gathering energy, protecting themselves, etc.) according to environmental contingencies andlinguistic constraints.

Although stupidity is not uniquely human, understanding our verbally based brand of it might help us cope with ourselves and perhaps avoid some of the psychological and philosophical pitfalls which have plagued us in the past. Certainly, we can begin by acknowledging that throughout history stupidity has been our constant companion. Thus, anyone studying it in a historical context should learn something fundamental about the human experience and gain some insight into how the human mind does not work.

The first thing the student of stupidity learns is that, along with our purely biological needs - food, water, etc., we need a schema which provides a program for behavior. The second is that we also need an ideology which explains the nature of the universe and our relation to it. The ideology is a conscious, organized expression of the verbal facet of the schema and forms a cognitive bridge between religious beliefs about the supernatural world and secular ideas derived from coping with the mundane problems of life. These beliefs and ideas need not necessarily be factually based; nor need they be logically consistent with each other, and indeed they seldom are. Their function is to promote group cooperation as people interact with their natural and cultural environments.

The problem with and for the ideology is that it is not experience per se but the schema that comes to define life by shaping perceptions according to its own irrational nature. This often means that unpleasant facts are not treated as information but as intellectual sinsbreaches of faith in the belief system. As psychologist Winston Churchill noted, the human mind recoils from terrifying facts and retreats into a kind of "Merciful numbness" -i.e., a stupor which may defy "Ideologic".

In real life, most political/economic systems do not have to make sense nor even be systematic: the important thing is that they function. Any outside observer committed to a rational analysis of events could not help but be bewildered by the de-velopment of modern governments and economies, for example. Nonetheless, as long as the people living with them believe in them, they (both the people and their nonsystematic systems) may survive and even flourish-at least for a while.

During their existence, "Establishments" are usually quite anti-empirical and unscientific in their adherence to obsolete or even incorrect theories about what they are doing. Those in power tend to be conservative - meaning they honor the ideas with which they grew up and perceive the world in terms of the values which took them to the top. Basically, leaders want to retain their power and are loath to acknowledge the existence of any problems they cannot solve without changing. Thus, their own continued predominance defines the context in which problems are considered. Throughout the ages, the eternal, ultimate political problem has been and remains that of controlling those in control, and the perennial abuse of power has invariably restedon the resistance of the mighty to any change in their point of view.
The failure of anyone to modify perceptions according to new combinations of developing environmental variables often leads to the extreme imbalanced condition everyone else re-cognizes as stupidity. This would happen even more often than it does except that most "Perceptual systems" are checked by conflicting systems most of the time. Thus, youthful enthusi-asm is checked by parental guidance; corporations are checked by government, which is checked by the people or other gov-ernments, etc. On the other hand, stupidity is induced when sys-tems which should check each other become mutually rein-forc-ing. The arms race was an example of this process, as two systems, which would have confronted each other in ages past, stimulated each other to excesses in the development of their military establishments. Only as recently as December, 1987, did the signing of an arms control treaty designed to restrict our capacity to annihilate ourselves interject an element of san-ity into this double helix of senseless insanity which had its origins in the compounding of our common cultural history up-on individual life experiences.

Ontogeny: The wonder of human culture is that anyone man-ages to grow up with anything like sense and sanity. Consider the fact that mostpeople start life with the handicap of parental love. Of all forms of emotionally induced blindness, this is the blindest, and most of us are lucky enough to get a double dose. As with others who love, parents are blind because they want to be, and for nearly two decades, the child is helpless to escape the best efforts of his parents to distort his self- image and sense of importance.

Whatever limitations culture may have, it certainly is efficient at transmitting stupidity from one generation to the next (as well as developing it anew). Children receive a basic lesson from their parents and other adults who gain some peculiar pleasure in denying reality to them. It is quite common to say to a small child, "What a big boy you are". Statements con-trary to the obvious may be more comforting than the truth-"My, what a scrawny little runt you are!"— and have the added advantage of preparing the child for the adult world in which accuracy is too commonly sacrificed to diplomacy.

In the first year, the child passes through a phase of cerebellar, motor control and forms a basic information processing schema. This is the first step in the construction of a general religious belief system which will guide and limit future be-havior. At this time, the child develops a fundamental sense of trust or mistrust, which is another source of future stupidity: later on, the individual will find himself mistakenly trusting the untrustworthy or suspiciously dismissing honest people with sincere intentions.

A cognitive correlate of trust is the concept of object permanence, which is formed by the age of 18 months. By this age, the child can represent by mental image objects no longer in sight. The underlying assumption is that objects are consistent - that they remain the same not only when viewed from different angles or distances but even when they cannot be viewed at all. Thus, different perceptions can be associated with a constant object. This has great potential for stupidity, in that an object may change and yet people will cling to their original image rather than adjust to the time altered reality.

The age of two years is the age of language, with actions and objects being represented by verbal as well as visual symbols. Classifying and grouping the symbols is accomplished accord-ing to the specific language of the social group. This is the pro-cess by which information is sorted and organized into cate-gories which may or may not reflect relevant relationships in the environment.

Along with the development of a child's cognitive world of ideas, a sense of rules and order also develops and undergoes transformation with maturation. 
For a young child, a rule is reality and is sacred because it is traditional. Even some adults never get beyond this stage, and, indeed, the basic rules of life, whatever they are, do not change. The older child comes to realize that stated rules are expressions of mutual agreement which function by promoting social cooperation through individual constraint.

Although the idea of rules may change, the system of assumed world order the young child inherits from his parents is a moral necessity to him. As he matures, he will be forced to resort to reason when his rules are challenged by people with other rules or by an amoral environment. He then may be pulled in a number of directions while trying to impose unity on the chaos of this experience.

For all their inventive play, young children are basically conservative. They hate change, as anyone who has dared alter a word in a bedtime story well knows. Their cognitive expectations are very precise with daily routine providing stability and a sense of safety in astrange, often unpredictable world.

Oddly enough, the extreme trauma of losing a parent in early childhood can induce a schema-busting persona. The survivor of such an experience is likely to break the frame of the known world -of what is known and assumed. Generally, however, the more uncertain the external world appears, the more tenaciously the schema is held and although it may occasionally if not chronically induce stupidity, its common presence indicates that, over all, it must be truly adaptive.

\section{References}

1. Tanner, T. 1996. Introduction to the Penguin Classic edition of J. Austin's Pride and Prejudice-which might have been ensubtitled "A Woman Changes Her Mind". Like, this warrants a book? For an account of "A Man Does Not", see King Lear by Shakespeare, W. Ca. 1605.

2. More, H. 1799. Strictures on the Modern System of Fe-male Education. VII. 195-196.

3. Pitkin, W. 1932. A Short Introduction to the History of Human Stupidity. Simon and Schuster; New York. 21. If any-thing, educated people tend to be a bit more likely than others to come up with cockamamie notions. (Aaronovitch, D. Voo-doo Histories. Riverhead Books; New York. 2010. 339.) As Fedor Dostoievsky tersely noted, "Man is stupid, phenomenally stupid”. Quoted on p. 173 of The Power of Stupidity by G. Livraghi. M\&A Publishers. Pescara; Italy. 2009.

4. Stanton, E., Anthony, S. and Gage, M. (Eds.) Ernestine Rose in The History of Women's Sufferage. Source Book Press; Rochester, NY. 1971. 1:442. This in direct defiance of Timothy 2:11-12-"Let a woman learn in silence". (Anony-mous. Ca. 100 A.D. Misattributed to St. Paul.) Misanthropy has a long venerable tradition dating back to our nomadic past when it was of some functional value. (Bronowski. 61.) It may have retained some value during the agricultural revolu-tion but less and less through the industrial revolution and the current age of computers. However, some ideas die hard.

5. Pitkin. op. it. 20.

6. Tuchman, B. 1984. The March of Folly. Knopf; NY. 46.

7. Koheleth. Ca. 235 B.C. Ecclesiastes. 2:16-17. (In the New English Bible, Chapters 7-10 are explicitly devoted to com-paringwisdom and folly.)
8. Matthew 5:22. In the King James Holy Bible, the quotation is: "Whoever shall say, 'Thou fool', shall be in danger of hell fire." The New English Bible softens this considerably: "...if he sneers athim (i.e., his brother) he will have to answer for it in the fires of hell." Regardless of which translation is more accurate, it was the wording and image in the older version which dominated thinking and shaped our attitudes and values for the past 400 years if not before.

9. Ripley, G. 1839. Letters on the Latest Form of Infidelity. Boston, MA. 98-99.

10. Celsus. ca. 178. True Word. Quoted in Origines Ada-mantius's Against Celsus; early 3rd century. And the tradition continued until at least 1717, when pirate Samuel Bellamy, who, in a fit of righteousness, compared his freedom favor-ably to the slavish conditions of those who put their faith in parsons who neither practice nor believe what they preach to knuckle-headed fools. (Quotation on page 28 of Pirates and Buccaneers of the Atlantic Coast by E. Snow. 1944.)

11. Holbach, P-H. 1999. Histoire critiques de Jesus Christ, Preface, in Oeuvres philophiques completes. (Complete philosophicalworks.) J-P Jackson. Ed. Editions ALIVE: Par-is. 726-735.

12. Scalia, A. Undated statement at a Knights of Columbus meeting cited in The Nine by J. Toobin. 2007. Doubleday; New York. 200.

13. Ephesians. 62 A.D. 5:4 and 5:17. This section is loaded with canny advice about how to be-like wives are subject in everything to husbands, who should love their wives as they love their own bodies, some parts of which are quite loveable.

14. Pitkin. op. cit. 25.

15. Tuchman. op. it. 7.

16. Halpern, D. 2002. Sex, lies, and audiotapes: The Clinton-Lewinsky scandal. In R. Sternberg (Ed.) Why Smart People Can Be So Stupid. Yale U. Press; New Haven, CT. 106.

17. Coulter, A. 2003. Treason. Crown Forum; NY. 162.

18. Judt, T. Thinking the Twentieth Century. Penguin; New York. 2012. 397.

19. Hanson, V. 2004. "If the Dead Could Talk". Hoover Di-gest. \#4, pp. 17-18.

20. Pitkin. op. cit. 25 ..

21. Shermer, M. 2011. The Believing Brain. Times Books.

22. Harman, G. 1995. Rationality. In E. Smith and D. Osher-son (Eds.) Thinking, Vol. 3, 32-58. Cambridge University Press; Cambridge, England.

23. Boorstin, D. 1998. The Seekers. Vintage; NY. 155.

24. Anderson, J. 1990. The Adaptive Character of Thought. Erlbaum; Hillsdale, NJ.

25. Proshansky, H. and Seidenberg, B. (Eds.) 1965. Basic Studies in Social Psychology. Holt, Rinehart and Winston; New York. Welles, J. 1988. Societal roles in self-deception. In J. Lockard and P.Paulhus (Eds.) Self-deception: An Adaptive Mechanism? Prentice Hall; Englewood Cliffs, NJ. 56-59.

26. Watson, R. Feb. 21, 2010. While fear and paranoia take control of rational voters. Sun-Sentinel; Fort Lauderdale, FL. 5F.

27. Stanovich, K. 2002. Rationality, intelligence, and levels of analysis in cognitive science: Is dysrationalia possible? In R. Sternberg (Ed.) Why Smart People Can Be So Stupid. Yale University Press; New Haven, CT. 125.

28. Harari, Y. Sapiens. Harper; New York. 2015.

29. Austin, E. and Deary, J. 2002. Personality Dispositions. In R. Sternberg (Ed.) Why Smart People Can Be So Stupid. Yale University Press; New Haven, CT. 191. 
30. Mishra, P. Age of Anger. Ferrar, Straus and Giroux; New York. 2017. 48.

31. Ibid. p. 89.

32. Sowell, T. 2009. Intellectual sand Society. Basic Books; New York. 1.

33. Woods, T. 2007. 33 Questions About American His-tory. Three Rivers Press; New York. 261.

34. Pitkin. op. cit. 165.

35. Hall, C. and Lindzey, G. 1970. Theories of Personality. Wiley; New York.

36. Richter, P. Cited on p. 51 of Mme. de Stael's Germany. New York. 1861.

37. Hodgkinson, T and H. v. d. Bergh. How to Sound Cul-tured. 2015. Publishers Group West; Berkeley, CA. p. 138.

38. Hayward, S. The Age of Reagan: The Fall of the Old Liberal Order. 2001. Three Rivers Press; New York. 693.

39. Nickerson, R. 1987. Why teach thinking? In. J. Baron and R. Sternberg (Eds.) Teaching Thinking Skills: Theory and Practice. Freeman; NY. 27-40.

40. Wilson, V. 2007. Fair Game. Simon and Schuster; New York. 302.

41. Pitkin. op. cit. 40.

42. Ibid. 41.

43. Schelling, T. 1966. Arms and Influence. Yale U. Press; New York. 93.

44. Hitler, A. July 21, 1944. Quoted on page 652 of Kershaw. 2000.

45. This Is Spinal Tap. (Movie.) 1984.

46. Voltaire, F. 1764. Dictionnaire Philosophique; Self-Love. Seealso: Turgenev, I. 1867. Smoke. The Modern Lib-rary; New York.111.

47. Billings, J. Undated quotation on page 772 of P. Mc-Williams's Ain't Nobody's Business If You Do. Prelude Press; Los Angeles, CA. 1993.

48. Lewicki, P. June 23, 1992. Quoted in "Your Unconscious Mind May Be Smarter Than You" by D. Goleman. The New York Times. C11.

49. McWilliams, P. Ain't Nobody's Business If You Do. Prelude Press; Los Angeles, CA. 1993. 188.

50. Fawcett, B. 2010. Mistakes That Changed History. Berkley Books; New York. Chap. 64.

51. Snyder, T. 2010. Quoted on p. 357 of Judt. op. cit.

52. Hebb, D. 1949. The Organization of Behavior.

53. Lewis, M. 2017. The Undoing Project. Norton; New York. 70.

54. British Broadcasting Company. Jan. 19, 2001. Published biography of Saddam Hussein.

55. Churchill, W. 1932. Thoughts and Adventures. Thorn-ton Butterworth; London. 15.

56. Bradley, J. The Boys Who Saved Australia. In What If? R. Cowley (Ed.). Putnam; New York. 2001. p. 690.

57. For a probing take on this general problem see The Out-rage starring Paul Newman and Clair Bloom. 1964. (DVD-2009) A westernized Rashomon.

58. Woodward, B. The War Within. Simon and Schuster; New York. 2008. Chap. 24.

59. Ayduk, O. and Mischel, W. 2002. When smart people behave stupidly. In R. Sternberg (Ed.) Why Smart People Can Be So Stupid. Yale University Press; New Haven, CT. 101.

60. Lau, R. and Russel, D. 1980. Attribution in the sports pages. J. of Personality and Social Psychology, 39, 29-38.

61.
Pitkin. op. cit. 14.

62. Holton, G. Jan. 1953. On the duality and growth of physical science. American Scientist, 41, 91. Dalton laid down the mutable law that no one could split an atom. (Bronowski. 150.)

63. Fawcett. op. cit. Chap. 65.

64. Pitkin. op. cit. 286. Put another way: Logic will get you from A to Z; to get anywhere else, you need imagination. (A. Einstein.)

65. Leuchtenburg, W. The American President. Oxford University Press; New York. 2015. p. 796.

66. Young, Dr. Mark J. Aug. 23, 2016. Personal communication from a retired shrink and an excellent amateur magician.

67. Lockard and Paulhus. op. cit.

68. Schramm, P. 1999. Hitler: The Man \& the Military Leader. Academy Chicago; Chicago, IL. 92.

69. Welles, J. Spring, 2009. Correcting Errors in Science: An Analytic Review. Journal of Information Ethics. Vol. 18, \#1, 16-20. Opposed to cogdis is F. Scott Fitzgerald's (1936.) insight that the mark of first rate mind is the ability to hold contradictory ideas at the same time and still function. For my money, Festinger is being super-egoish: His view is the way a reasonable mind should function. He and his have gathered a lot of supporting data, but to maintain their theory, they have to ignore a lot of street behavior which contradicts their view. The test set up by scientists showhow the mind can function-not necessarily how it does function. More perplexing and confusing is the fact that even a first rate mind can function well with just a half-baked idea if it is gratifying. (Dolnick. 251.)

70. Whitman, W. 1855. Song of Myself.

71. Tuchman. op. cit. 5 .

72. Halle, K. 1967. The Irrepressible Churchill: A Treasury of Winston Churchill's Wit. World Publishing; NY. 153.

73. Masses Publishing Co. v. Patten, 244 Federal Reporter 535-541. (S.D. N.Y. 1917)

74. Gup, T. 2007. Nation of Secrets. Doubleday; NY. 63.

75. Wells, H. 1931. The Work, Wealth and Happiness of Mankind. Chap. 11.

76. Thucydides. Ca. 410 B.C. History of the Peloponnesian Wars.

77. Janis, I. 1982. Groupthink. Houghton Mifflin; Boston, MA. 142.

78. Hayward, S. The Age of Reagan: The Conservative Counterrevolution. 2009. Crown; New York. 329 and 331. John. Ca. 100 A.D. Revelation 16:16.

79. Tuchman. op. cit. 5.

80. Smith, R. Sarason, I. and Sarason, B. 1982. Psychology: The Frontiers of Behavior. Harper \& Row; New York. 487.

81. Cosmides, L., and Tooby, J. 1987. From evolution to be-havior: Evolutionary psychology as the missing link. In J. Du-pre (Ed.) The Latest on the Best: Essays on Evolution and Optimality. MIT Press; Cambridge, MA. 277-306.

82. Cottrell, C. and Neuberg, S. Jan. May 2005. Different emotional reactions to different groups. J. Personality and Soc. Psyc., 88, 5, 770-789.

83. Westion, M. Fall, 1997. Diet for a Zomblified Planet. Paranoia. \#14, 300-302.

84. Smith, et al. op. cit. 388.

85. Francis, G. Adventures in Being Human. Basic Books; New York. 2015. 192.

86. Roosevelt, President F. D. Feb. 5, 1937. Explanation for packing the Supreme Court. Quoted in Shesol, J. 2010. Su-preme Power. Norton; New York. 295-296. 
87. Russell, B. Cited on page 182 of Excellence Without a Soul by H. Lewis. Public Affairs; New York. 2006. On the other hand, stupidity may be humanity's way of continuing. If intelligence reigned supreme, almost no one would be born, (Erasmus. 1508.) and the human race would become extinct.

88. Hyman, R. 2002. Why and when are smart people stupid? In R. Sternberg (Ed.) Why Smart People Can Be So Stu-pid. Yale University Press; New Haven, CT. 4.

89. Pitkin. op. cit. ix.

90. Ibid. 82.

91. Ibid. 307. Secondat, C. (Baron de Montesquieu.) The Spir-it of the Laws; Book XIV. 1848. Generally, geographic deter-minismis unpopular with psychologists, who like to think peo-ple are free to shape their behavior. (Fukuyama. 2014. 236.)

92. Spary, E. Utopia's Garden. Chicago University Press; Chicago, IL. 2000. pp. 113-114.

93. Sachs, J. Tropical Underdevelopment. National Bureau of Economic Research Working Paper No. 8119. Cam-bridge, MA. 2001.

94. Diamond, J. Guns, Germs, and Steel. Norton; New York. 2005. 22.

95. Toynbee, A. 1934. A Study of History. II; 65.

96. Ibid. 50.

97. Dudley, R. 2002. Fermenting fruit and the historical eco-logy of ethanol ingestion. Addiction; 97, 381-388.

98. Muller, H. 1966. The Loom of History. Oxford University Press; New York. 39.

99. Blom, P. 2010. A Wicked Company. Basic Books; New York. ix.

100. Durbin, M. 1973. Cognitive anthropology. In The Hand-book of Social and Cultural Anthropology edited by J. Honigmann. Rand McNally; Chicago, IL. 447-478.

101. Briffault, R. 1936. Reasons for Anger. 33.

102. Evans, H. and Eberhard, M. 1970. The Wasps. U. of Michi-gan Press; Ann Arbor, MI.

103. Wilson, E. 1975. Sociobiology. Harvard University Press; Cambridge, MA. 381-382.

104. Seligman, M. 1970. On the generality of the laws of learn-ing. Psychological Review, 77, 406-418.

105. Garcia, J., McGowan, B., Ervin, F. and Koelling, R. 1968. Cues: their relative effectiveness as a function of the reinforcer. Science, 160, 794-795.

106. Bolles, R. 1980. Ethological learning theory. In Theories of Learning: A Comparative Approach edited by G. Gazda and R. Corsini. Peacock; Itaska, IL.

107. Heck, L. Über die Bildung einer Assoziation beim Regenwurm auf Grund von Dressurversuchen. Lotos Naturwiss. Zsch., 68, 168189. 1920.

108. Wilson. 1975. op. cit. 375.

109. Smith, N. The advantages of being parasitized. Nature, 219 (5155), 690-694. 1968.

110. Wilson. 1975. op. cit. 159.

111. Lorenz, K. King Solomon's Rings. Thomas Y. Crowell Company; New York. 1952. 109.

112. Ibid. 110.

113. Meyerriecks, A. 1972. Man and Birds: Evolution and Behavior. Pegasus, Bobbs-Merrill Co.; Indianapolis, IN.

114. Skinner, B. 1948. "Superstition" in the pigeon. J. Exp. Psyc., 38, 168-172.

115. Goodall, J. 1971. In the Shadow of Man. Houghton Mifflin; Boston, MA. 52.
116. Köhler, W. 1959. The Mentality of Apes. Vintage; New York. 173174.

117. Kalb, C. Andy Warhol Was a Hoarder. National Geo-graphic; WDC. 2016. 50.

118. Washburn, S. and Hamburg, D. 1965. The implications of primate research. In Primate Behavior: Field Studies of Monkeys and Apes edited by I. DeVore. Holt, Rinehart and Winston; New York. 620.

119. Pitkin. op. cit. 80 .

120. Sternberg, R. 2002. Smart people are not stupid, but they sure can be foolish. In R. Sternberg (Ed.) Why Smart Peo-ple Can Be So Stupid. Yale U. Press; New Haven, CT. 236.

121. Darwin, C. Ca. 1859. Correspondence of Charles Dar-win. 7:340.

122. Pitkin. op. cit. 54.

123. Ibid. 99.

124. Ibid. 67.

125. Carlyle, T. 1833-1834. Sartor Resartus. Bk. II, Ch. 4.

126. Leakey, R. and Lewin, R. Origins. Dutton; New York. 1977. 208.

127. Auel, J. 1980. The Clan of the Cave Bear. Crown; NY.

128. Smith, et al. op. cit. p. 368.

129. Leakey and Lewin. op. cit. p. 248.

130. Wilson. 1975. op. cit. p. 550.

131. Ibid. p. 569.

132. Madison, J. 1787. Quoted in The Papers of James Madison edited by Hutchinson, W. et al. University of Chi-cago Press; Chicago, IL. 1962-1991. Vol. 9, pp. 356-357; and Vol. 10 (1977), p. 214.

133. Leakey and Lewin. op. cit. p. 208.

134. Churchill, W. Feb. 1954. Quoted: 139f of Thomas.

135. Arnold, T. The Folklore of Capitalism. Yale University Press; New Haven, CT. 1937. p. 68.

136. Lyttleton, R. The Gold effect. In Duncan, R. and Weston-Smith, M. (eds.) The Encyclopedia of Delusions. Wallaby; New York. 1979. p. 192.

137. Kennedy, Pres. J. Quoted in Robert Kennedy and His Times by A. Schlesinger, Jr. Houghton Mifflin; Boston, MA. 1978. p. 623.

138. Schlesinger, Jr., A. The Imperial Presidency. Houghton Mifflin; Boston, MA. 1973. p. 164. Gore, Vice President A. Paraphrased by T. Oliphant in the article "Clinton will need to persevere in face of resentful right—since it's wrong." Sun-Sentinel. Fort Lauderdale, FL. Jan. 19, 1994. 23A. (As smug a statement by the liberal left as can be found.)

139. Plato. Ca. 370 B.C. Phaedrus. Love is listed as a fourth type of mania after poetry, prophesy and religious ecstacy.

140. Pitkin. op. cit. 438.

141. Freud, A. 1966. The Ego and the Mechanisms of Defense. International Universities Press; New York. 84.

142. Bronowski, J. The Ascent of Man. Little, Brown \& Co.; Boston, MA. 51.

143. Erikson, E. 1974. Dimensions of a New Identity: The 1973 Jefferson Lectures in the Humanities. Norton; NY.

144. Piaget, J. 1932. The Moral Judgment of the Child. Macmillan; New York. Btw, Piaget was very much a Lockian "Nurturist".

145. Ibid.

146. Ibid.

147. Ibid.

148. Clinton, H. Apr. 6, 1993. Liz Carpenter Lecture at the University of Texas.

149. Smith, et al. op. cit. 366.

150. Mezan, P. Dr. Quoted in Gladwell. 2013. 153 